\title{
Identification of Time-varying Parameters of a Monthly Budyko Function and its Implications
}

\author{
Weibo Liu ${ }^{1}$, Pan Liu ${ }^{1}$, Lei Cheng ${ }^{1}$, Xiaojing Zhang ${ }^{1}$, and Liting Zhou ${ }^{1}$ \\ ${ }^{1}$ State Key Laboratory of Water Resources and Hydropower Engineering Science
}

April 8, 2021

\begin{abstract}
The Budyko framework, which can describe a simple but useful partitioning of precipitation under supply and energy limits, is used widely to estimate evapotranspiration (ET). Previous studies have investigated time-variant Budyko functions on annual or interannual scales but seldom on the intra-annual scale. This study used a monthly two-parameter $\left(x\right.$ and $\left.y_{0}\right)$ Budyko function and three schemes that considered single observations (ET or streamflow (Q)) and dual observations (ET and Q) to assimilate the time-varying parameters using the ensemble Kalman filter method. The study considered the contiguous USA (CONUS) using the Model Parameter Estimation Experiment dataset. The time-varying parameters were explained on the basis of time series analysis and correlation with meteorological data. Three conclusions were as follows. (1) The identified time-varying parameters ( $x$ and $y_{0}$ ) of the Budyko function could effectively simulate ET. (2) The assimilation using only ET observations could identify a plausible set for parameter $x$ but was inadequate for $y_{0}$. (3) Most time-varying parameters exhibited a 12-month period, and the trend and change points detected for Midwest CONUS were related to anthropogenic influences such as extraction and use of groundwater. The findings show that changing environment can be detected by using the proposed time-varying parameters of the Budyko function.
\end{abstract}

\section{Hosted file}

Manuscript .pdf available at https ://authorea.com/users/406513/articles/517136-identificationof-time-varying-parameters-of-a-monthly-budyko-function-and-its-implications 